\title{
PENGARUH KUALITAS PELAYANAN DAN WORD OF MOUTH ( WOM ) TERHADAP KEPUTUSAN PEMBELIAN
}

\author{
Heny Herawati \\ Fakultas Ekonomi dan Bisnis Universitas Islam As-Syafi'iyah \\ henyherawati41@gmail.com
}

\begin{abstract}
This study aims to determine the influence of Service Quality and Word of Mouth (WOM) on Purchasing Decisions at PT. Hijrah Insan Karima because at this time there have been many threats and competitors in the world of selling concrete and baja ringan iron. The subject in this study was the Histeel company that had been established since 2008. The total population studied in this study was 465,000 respondents. The sampling technique uses slovin formula and obtained a sample of 100 respondents, namely consumers PT. Hijrah Insan Karima. The statistical methods used in this study are the Classical Assumption test, Regression Analysis, Correlation Analysis, and Hypothesis Test. The analytical tool used in this study is SPSS version 21. The results of this study indicate that Service Quality and Word of Mouth (WOM) simultaneously have a significant effect on purchasing decisions. Tested with multiple correlations, there is a simultaneous contribution value of $R=0.592$ or $59.2 \%$ influential and $40.8 \%$ influenced by other variables and the results of the t test sig X1 value of $0.006<0.05$ and X2 of 0.000 $<0.05$ means Service Quality and Word of Mouth (WOM) variables influence Purchasing Decisions.
\end{abstract}

Keywords: Service Quality, Word of Mouth (WOM), Purchasing Decisions

\begin{abstract}
Abstrak
Penelitian ini bertujuan untuk mengetahui Pengaruh Kualitas Pelayanan dan Word Of Mouth (WOM) Terhadap Keputusan Pembelian Pada PT. Hijrah Insan Karima karena pada saat ini telah banyak ancaman dan pesaing dalam dunia penjualan besi beton dan baja ringan. Subject dalam penelitian ini adalah perusahaan Histeel yang sudah berdiri sejak tahun 2008. Jumlah populasi yang diteliti dalam penelitian ini sebanyak 465.000 responden. Tekhnik pengambilan sampel menggunakan rumus slovin dan diperoleh sampel sebanyak 100 responden yaitu konsumen PT. Hijrah Insan Karima. Metode statistik yang digunakan dalam penelitian ini adalah uji Asumsi Klasik, Analisis Regresi, Analisis Korelasi, Dan Uji Hipotesis. Alat analisis yang digunakan dalam penelitian ini adalah SPSS versi 21. Hasil penelitian ini menunjukan bahwa Kualitas Pelayanan dan Word Of Mouth (WOM) secara simultan berpengaruh signifikan terhadap keputusan pembelian. Diuji dengan korelasi berganda terdapat nilai kontribusi secara simultan sebesar $\mathrm{R}=0,592$ atau 59,2\% berpengaruh dan 40,8 \% dipengaruhi oleh variabel lain dan hasil uji t nilai sig $\mathrm{X}_{1}$ sebesar $0,006<0,05$ dan $\mathrm{X}_{2}$ sebesar $0,000<0,05$ artinya variabel Kualitas Pelayanan dan Word Of Mouth (WOM) berpengaruh terhadap Keputusan Pembelian.
\end{abstract}

Kata Kunci : Kualitas Pelayanan, Word Of Mouth (WOM), Keputusan Pembelian 


\section{Latar Belakang}

Pemerintahan Indonesia saat ini sedang giat-giatnya melakukan pembangunan infrastruktur guna peningkatan perekonomian negara dan mempermudah memberikan pelayanan kepada masyarakat. Untuk mendukung pembangunan infrastruktur tersebut maka penggunaan baja merupakan salah satu indikator pemenuhan kebutuhan pekerjaan infrastruktur tersebut dalam rangka mempercepat kemajuan suatu negara dalam bidang pembangunan (www.Republika.co.id).

Sektor baja yang memiliki peran penting dalam pembangunan nasional, maka dalam memenuhi kebutuhan, pengadaan dan pelaksanaannya diatur oleh pemerintah dalam hal ini melalui peraturan Mentri Perdagangan Republik Indonesia nomor 110 tahun 2018 tentang ketentuan import besi dan baja panduan dan produk turunannya. Hal ini untuk membatasi import besi dan baja yang berlebihan dan untuk melindungi industry besi dan baja dalam negri. Perusahaan dan para pelaku usaha di bidang ini harus siap untuk menghadapi persaingan didunia usaha sektor logam dan baja yang semakin ketat dan kompetitif.. Dari data BPS tahun 2020, diperoleh data Import Pipa besi dan Baja menurut asalnya dari tahun 2009 hingga tahun 2019 mengalami fluktuatif seperti yang tercantum pada table dibawah ini :

Tabel 1

Data Impor Pipa Besi dan Baja Menurut Negara Asal 2009-2019 ( Berat Bersih: 000 ton )

\begin{tabular}{|l|rr|r|r|r|r|r|r|r|r|r|}
\hline \multicolumn{1}{|c|}{ Negara Asal } & $\mathbf{2 0 0 9}$ & $\mathbf{2 0 1 0}$ & $\mathbf{2 0 1 1}$ & $\mathbf{2 0 1 2}$ & $\mathbf{2 0 1 3}$ & $\mathbf{2 0 1 4}$ & $\mathbf{2 0 1 5}$ & $\mathbf{2 0 1 6}$ & $\mathbf{2 0 1 7}$ & $\mathbf{2 0 1 8}$ & $\mathbf{2 0 1 9}$ \\
\hline Tiongkok / Cina & 268,4 & 306,8 & 328,3 & 509,2 & 465,8 & 407,7 & 239,7 & 175,9 & 195,7 & 280,4 & 266,7 \\
\hline Jepang & 105,8 & 233,2 & 156,2 & 332,5 & 151 & 129,6 & 73,6 & 55,9 & 152,2 & 114,8 & 90,8 \\
\hline Singapura & 100,6 & 115,2 & 76,7 & 97,4 & 92,6 & 86,3 & 35,8 & 28,8 & 29 & 22,6 & 67,0 \\
\hline Amerika Serikat & 4,4 & 4,2 & 5,5 & 9,4 & 13,1 & 5,8 & 1,2 & 2,2 & 1,8 & 9,1 & 1,1 \\
\hline Korea Selatan & 38,3 & 33 & 39,5 & 66,2 & 68,2 & 59,5 & 2,1 & 10,7 & 28,4 & 36,3 & 52,5 \\
\hline Thailand & 9,4 & 10,9 & 10,4 & 10,5 & 15,2 & 11,1 & 20,3 & 2,4 & 4,7 & 4,1 & 5,9 \\
\hline Jerman & 5,4 & 18,9 & 10,1 & 8,4 & 263,6 & 20,6 & 2,9 & 5,2 & 21,8 & 24,8 & 18.1 \\
\hline Italia & 6 & 25,5 & 35,7 & 41,6 & 28,1 & 38,9 & 17,5 & 10,1 & 9,9 & 20,7 & 16,1 \\
\hline India & 5,4 & 2,5 & 59,3 & 76,7 & 3,6 & 4,4 & 17,5 & 1,9 & 3,4 & 5,2 & 33.3 \\
\hline Perancis & 9,6 & 29,8 & 47 & 28,4 & 37,4 & 7,6 & 3,7 & 0,6 & 1,1 & 2,3 & 0 \\
\hline Taiwan & - & - & - & - & - & - & - & - & - & - & - \\
\hline Lainnya & 40,2 & 62,3 & 100,5 & 135,7 & 90,3 & 115,8 & 29,2 & 32,1 & 94,3 & 103,6 & 49.8 \\
\hline \multicolumn{1}{|c}{ Jumlah } & 593,5 & 842,3 & 869,2 & 1316 & 1228,9 & 887,3 & 443,5 & $\mathbf{3 2 6}$ & $\mathbf{5 4 2}$ & $\mathbf{6 2 3 , 9}$ & 660,1 \\
\hline
\end{tabular}

Sumber data: https://www.bps.go.id 2020 
PT. Hijrah Insan Karima atau yang lebih dikenal dengan nama Hi Steel adalah sebuah perusahaan yang menjadi distributor dalam penjualan besi beton dan baja ringan di Indonesia. PT. Hijrah Insan Karima berdiri sejak tahun 2008. Memiliki 7 cabang di Indonesia, yang telah memiliki beberapa tempat diantaranya di Jakarta, Bekasi, Cibubur, Karawang, Bogor, Tangerang, Cirebon dan Surabaya , dengan Histeel Bekasi menjadi pusatnya dengan beralamat dijalan Wibawa Mukti II no. 68 Jatiasih 17146 Bekasi Jawa Barat

Berdasarkan data yang peneliti peroleh dari perusahaan bahwa pada tahun 2018 PT. Hijrah Insan Karima atau Histeel diketahui memiliki data penjualan perusahaan yang belum maksimal (mengalami fluktuatif kenaikan dan penurunan penjualan) atau tidak sesuai dengan target yang diinginkan perusahan seperti yang tercantum pada tabel 2

Tabel 2

Data Penjualan Januari-Desember 2018

\begin{tabular}{|c|c|}
\hline Januari & $\mathrm{Rp} \quad 928.604 .559$ \\
\hline Februari & $\operatorname{Rp} 1.233 .475 .650$ \\
\hline Maret & $\operatorname{Rp} 1.903 .770 .707$ \\
\hline April & $\mathrm{Rp} 1.219 .901 .518$ \\
\hline Mei & Rp 1.617.787.605 \\
\hline Juni & $\mathrm{Rp} \quad 441.904 .426$ \\
\hline Juli & Rp 1.295.622.839 \\
\hline Agustus & Rp 1.691.662.521 \\
\hline September & $\operatorname{Rp} 2.321 .546 .907$ \\
\hline Oktober & $\operatorname{Rp} 1.713 .866 .312$ \\
\hline November & $\mathrm{Rp} 1.445 .561 .034$ \\
\hline Desember & $\mathrm{Rp} \quad 928.604 .559$ \\
\hline
\end{tabular}

Sumber data: Histeel, 2018

Berdasarkan data penjualan diatas, maka penulis mencoba untuk melakukan penelitian untuk mengetahui apa yang menjadi faktor konsumen untuk melakukan keputusan pembelian dilihat dari segi kualitas pelayanan dan WOM (Word Of Mouth) . Apakah kualitas pelayanan dan Word Of Mouth yang sudah diterapkan dalam perusahaan berpengaruh terhadap keputusan pembelian, dan seberapa besar pengaruhnya terhadap keputusan pembelian. 
Layanan online merupakan salah satu cara untuk bagaimana dapat membantu konsumen dalam memudahkan mencari konten yang berbeda-beda dan membuat konten baru dari konten yang telah ada (Prasad, 2017). Dengan semakin pesatnya perkembangan media sosial akan menjadi sebuah berita gembira bagi para pemasar / markerter untuk dapat memasarkan produknya dan memberikan layanan/service terbaik bagi konsumennya (Ma, 2015). Saat ini media sosial dapat menjadi salah satu layanan yang paling diminati karena dapat mempengaruhi perilaku konsumen di seluruh dunia (Prasad, 2017). (Jalilvand, 2012), (Abubakar, 2016), (Sen, 2007) menyatakan bahwa komunikasi yang dilakukan dalam pemasaran dengan menggunakan E-WOM memiliki pengaruh yang sangat kuat dan peran penting terhadap keputusan pembelian baik yang dilakukan secara langsung maupun tidak langsung, dan konsumen memiliki tingkat kepercayaan yang tinggi terhadap informasi tersebut berdasarkan dari mana sumber informasi itu diperoleh (Abubakar, 2016).

Word of Mouth memiliki pengaruh penting dalam keputusan pembelian dan dalam dapat membentuk perilaku konsumen (Jalilvand, 2012). Word of Mouth dapat juga memiliki kekuatan penting dalam hal memberikan informasi yang valid dan reliabel, sehingga jenis komunikasi berupa pesan non commercial yang memiliki tingkat persuasive yang lebih tinggi dengan kepercayaan dan kredibilitas yang tinggi pula (Jalilvand, 2012). Dengan adanya perubahan di era digital saat ini menggeser saluran Word of mouth (WoM) menjadi Electronic Word of Mouth (E-WoM) dimana informasi yang diberikan dilakukan tanpa perlu adanya tatap muka dan tanpa mencari atau meminta informasi secara langsung (De Bruyn, 2008).

Tingkat kepercayaan seseorang terhadap suatu informasi dapat ditentukan dari mana sumber informasi tersebut berasal (Abubakar, 2016). Kemudahan untuk mendapatkan akses dengan jangkauan yang tinggi, akan menjadi lebih efektif bila dibandingkan dengan melalui komunikasi langsung (word-of-mouth offline) (Abubakar, 2016). Ditegaskan oleh (Chevalier, 2006) bahwa komunikasi E-WOM telah menjadi platform yang sangat penting bagi pengguna / konsumen. Dimana E-WOM memainkan peran penting dalam mempengaruhi sikap serta keputusan pembelian (Abubakar, 2016).

Dengan demikian maka keputusan pembelian merupakan sebuah keputusan seseorang yang akan memilih salah satu dari beberapa alternative pilihan yang ada. 
Menurut Setiadi (2003) Keputusan pembelian merupakan proses penyelarasan yang mengkombinasikan antara pengetahuan serta sikap untuk mengevaluasi dua atau lebih alternatif perilaku pembelian dan memilih salah satu diantaranya. Dengan demikian konsumen dihadapkan kepada banyak pilihan produk yang ada di pasar dan harus memilih salah satu diantaranya yang nantinya pilihan tersebut akan menjadi produk yang akan dibeli konsumen.

(Kotler, P. and Armstrong, 2013) mengatakan bahwa keputusan pembelian merupakan tahapan dimana konsumen akan membuat preferensi terhadap produk / merek yang berada di pasaran dan bagaimana mengambil keputusan untuk memilih produk mana yang akan beli diantara produk / merek yang ada tersebut . Sebelum konsumen memustuskan untuk melakukan pembelian biasanya konsumen akan melakukan pertimbangan dengan melihat dari berbagai faktor baik dari segi harga , kualitas, dan produk. Biasanya konsumen akan melakukan pembelian dengan melihat review yang ada serta dari pengalaman konsumen / pembeli sebelumnya.

Ada lima tahapan dalam proses pengambilan keputusan yaitu (1) Pengenalan Masalah, (2) Pencarian Informasi, (3) Evaluasi Alternatif, (4) Keputusan Membeli, (5) Perilaku Pasca Pembelian. Dan pembelian bukanlah akhir dari proses keputusan konsumen, namun berlanjut hingga pembelian tersebut menjadi suatu pengalaman bagi konsumen dalam menggunakan produk yang dibeli tersebut. Dari pengalaman pembelian tersebut akan menjadi pertimbangan untuk pengambilan keputusan pembelian selanjutnya di masa yang akan datang (Ma'ruf, 2005).

Penelitian yang dilakukan sebelumnya oleh Ariz Budi Satria (2016) yang berjudul “ pengaruh kualitas pelayanan, product knowledgedan word of mouth terhadap proses pengambilan keputusan pembelian pada Bengkel MJV audio dan variasi mobil". Dengan hasil penelitian bahwa secara parsial menunjukkan kualitas pelayanan, product knowledge dan word of mouth berpengaruh signifikan dan positif terhadap proses pengambilan keputusan pembelian pada Bengkel MJV audio dan variasi mobil.

Sedangkan penelitian yang dilakukan oleh Desi Mas'illatul Khasanah (2020) yang berjudul "pengaruh kualitas produk, word of mouth (wom), dan kualitas pelayanan terhadap keputusan pembelian suku cadang Bengkel Resmi Honda Ahass 10349 Setia Kawan Motor Lumajang” Dengan hasil Secara simultan bahwa variabel kualitas produk, 
word of mouth (wom), dan kualitas pelayanan berpengaruh positif dan signifikan terhadap keputusan pembelian

Berdasarkan latar belakang tersebut, peneliti tertarik untuk melakukan penelitian yang diberi judul "MODEL KUALITAS PELAYANAN DAN WOM (WORD OF MOUTH) TERHADAP KEPUTUSAN PEMBELIAN ( study Kasus pada PT Hijtrah Insan Karima )"

\subsection{Perumusan Masalah}

Berdasarkan uraian latar belakang penelitian tersebut, maka masalah yang diidentifikasikan oleh penulis adalah :

1. Apakah Kualitas Pelayanan mempengaruhi Keputusan Pembelian pada konsumen PT. Hijrah Insan Karima?

2. Apakah WOM (Word Of Mouth) mempengaruhi Keputusan Pembelian pada konsumen PT. Hijrah Insan Karima?

\subsection{Tujuan Penelitian}

Adapun tujuan dari penelitian ini adalah:

1. Untuk mengetahui Apakah Kualitas Pelayanan mempengaruhi Keputusan Pembelian pada konsumen PT. Hijrah Insan Karima

2. Untuk mengetahui apakah WOM (Word Of Mouth) mempengaruhi Keputusan Pembelian pada konsumen PT. Hijrah Insan Karima

\section{Landasan Teori}

\subsection{Keputusan Pembelian}

(Tjiptono 2012) menyatakan bahwa keputusan pembelian merupakan sebuah proses dimana konsumen mengenal masalahnya, mencari informasi dan mengevaluasi alternatif tersebut, yang kemudian mengarah kepada keputusan pembelian. (Suparyanto 2015) menyatakan indikator keputusan pembelian terdiri dari:

1. Pengenalan Kebutuhan

2. Pencarian Informasi

3. Evaluasi Alternatif

4. Keputusan Pembelian

5. Perilaku Pasca Pembelian 


\subsection{Kualitas Pelayanan}

( Zeithaml 2014 ) mendefinisikan kualitas pelayanan sebagai suatu kesenjangan atau ketidaksesuaian antara harapan dan keinginan konsumen dengan persepsi konsumen. Kualitas pelayanan yang diterima konsumen dinyatakan dalam besarnya ukuran kesenjangan / ketidaksesuaian antara harapan atau keinginan konsumen dengan tingkat persepsi mereka.

Ada 2 faktor utama dalam kualitas pelayanan yaitu Pelayanan yang diharapkan (expected service) dan pelayanan yang dipersepsikan (perceived service)(Tjiptono 2016). (Sopiah 2015) menyatakan bahwa ada 5 indikator Kualitas Pelayanan, yaitu:

1. Keandalan (Reliability) yaitu kemampuan untuk dipercaya dalam memberikan pelayanan yang tepat waktu.

2. Daya Tanggap (Responsiveness) yaitu kemauan marketing untuk memberikan pelayanan yang dibutuhkan konsumen.

3. Jaminan (Assurance) yaitu untuk menghilangkan sifat keragu-raguan konsumen.

4. Empati (Empathy) yaitu sikap personal untuk memahami kebutuhan konsumen.

5. Produk fisik (Tangibles) yaitu tersedianya fasilitas fisik dan sarana komunikasi.

\subsection{WOM (Word Of Mouth)}

(Kotler, P. and Armstrong, 2013) menyatakan bahwa Word of Mouth Communication merupakan proses komunikasi dari mulut ke telinga yang berupa pemberian rekomendasi terhadap suatu produk atau jasa baik secara individu maupun kelompok. Rusman Latief (2018) menyatakan bahwa WOM (Word Of Mouth) adalah satu-satunya metode promosi untuk pelanggan yang dilakukan dari pelanggan ke pelanggan. WOM adalah saluran komunikasi yang dapat dipercaya karena kejadiannya bermula dari pelanggan yang sudah pernah mengkonsumsi sebuah produk atau menggunakan jasa perusahaan dan memperoleh kepuasan kemudian merekomendasikannya kepada orang lain tentang pengalamannya.

(Sumardy 2011) WOM menyatakan ada 3 hal yang menjadi indikator WOM (Word Of Mouth) yaitu :

1. Customer do the talking

Konsumen memiliki kemauan untuk membicarakan hal-hal yang baik tentang kualitas produk dan pelayanan kepada orang lain. 


\section{Do promoting}

Merekomendasikan produk perusahaan kepada orang lain.

3. Customer do selling

Dorongan terhadap teman dan relasi untuk melakukan pembelian terhadap produk dan jasa perusahaan.

\section{Methode Penelitian}

\subsection{Variabel dan Pengukuran}

"Variabel Penelitian adalah suatu hal yang berbentuk apa saja yang ditetapkan oleh peneliti untuk dipelajari dengan tujuan untuk memperoleh informasi dan kemudian ditarik kesimpulannya”. (Sujarweni 2019)

Variabel yang digunakan dalam penelitian ini adalah sebagai berikut:

1. Independen Variabel (Variabel Bebas). Terdiri dari :

$\mathrm{X} 1$ = Kualitas Pelayanan dan

$\mathrm{X} 2=$ WOM (Word Of Mouth)

2. Dependen Variabel (Variabel Terikat), Terdiri dari :

$\mathrm{Y}=$ Keputuan Pembelian

\subsection{Pengukuran}

Skala Likert digunakan untuk mengukur persepsi, pendapat dan sikap seseorang atau sekelompok orang tentang fenomena sosial (Sugiyono,2013). Skala Likert merupakan alat untuk mengukur (mengumpulkan data dengan cara "mengukurmenimbang") yang "itemnya" (poin-poin pertanyaannya) berisikan pilihan yang bertingkat. Seperti, Sangat Setuju ( 5 ), Setuju ( 4 ), Kurang Setuju ( 3 ), Tidak Setuju (2) dan Sangat Tidak Setuju ( 1 )

\subsection{Populasi dan Sample}

\subsubsection{Populasi}

Populasi yang diambil dari PT. hijrah Insan Karima adalah 965.000 orang, terdiri dari pengunjung website dan media sosial Histeel per tahun 2019.

\subsubsection{Sampel}

Untuk menentukan ukuran sampel maka digunakan Rumus Slovin dengan kesalahan pengambilan sampel yang diinginkan sebesar (10\%) sebagai berikut: 


$$
\begin{aligned}
& \mathrm{n}=\frac{\mathrm{N}}{1+\mathrm{N} \cdot e^{2}} \\
= & \frac{965.000}{1+965.000(0.01)} \\
= & 99,9 \text { sampel (dibulatkan menjadi } 100 \text { orang) }
\end{aligned}
$$

Jadi Sampel Penelitian untuk populasi 965.000 orang yang dilakukan PT HIJRAH INSAN KARIMA adalah sebanyak 100 orang.

\subsection{Uji Instrument}

Uji yang digunakan dalam penelitian ini adalah Uji Validitas dan uji reliabilitas Uji validitas digunakan untuk mengukur sah atau tidaknya suatu kuesioner. Uji Reliabilitas untuk mengetahui sejauh mana hasil dari pengukuran dengan menggunakan objek yang sama akan menghasilkan data yang sama.

\subsection{Metode Analisis Data}

Uji analisis yang digunakan dalam penelitian ini dengan menggunakan Uji Asumsi Klasik diantaranya adalah, Uji Normalitas, Uji Multikolinieritas, dan Uji Heteroskedastisitas, uji Analisa regresi, Uji Analisis Korelasi, dan Uji T

\section{Pembahasan}

\subsection{Analisa Karakteristik Responden Penelitian}

Karakteristik responden pada penelitian ini dapat ditinjau dari usia, jenis kelamin, pendidikan terakhir dan pekerjaan diantaranya :

Tabel 3. Karakteristik Responden Penelitian

\begin{tabular}{llc}
\hline usia & 18- 30 Tahun & 50 Orang \\
& 31- 40 Tahun & 17 Orang \\
& $41-50$ Tahun & 21 Orang \\
& $>50$ Tahun & 12 Orang \\
jenis kelamin & laki-laki & 52 Orang \\
\multirow{3}{*}{ pendidikan terakhir } & Perempuan & 48 Orang \\
& SD & 4 Orang \\
& SMP & 12 Orang \\
& SMA & 42 Orang \\
& DIPLOMA & 6 Orang \\
& STRATA 1 & 30 Orang
\end{tabular}




\begin{tabular}{|c|c|c|}
\hline \multirow{7}{*}{ pekerjaan } & STRATA 2 dan 3 & 6 Orang \\
\hline & PNS & 14 Orang \\
\hline & Pegawai Swasta & 32 Orang \\
\hline & Mahasiswa & 3 Orang \\
\hline & Aplikator & 10 Orang \\
\hline & Wiraswasta & 24 Orang \\
\hline & Kontraktor & 17 Orang \\
\hline
\end{tabular}

\subsection{Uji Instrumen/Uji Prasyarat}

\subsubsection{Uji Hasil Validitas}

Uji Validitas dilakukan untuk melihat ketepatan dan kecermatan alat ukur yang digunakan dalam melakukan ukuran fungsi penelitian . Skor butir yang diteliti sebanyak 20 responden dari total responden sebanyak 100 orang, butir instrument dinyatakan valid jika harga koefisien Product Moment (ryx) atau $r_{\text {hitung }}$ lebih besar dari $r_{\text {tabel }}\left(r_{\text {hitung }}>r_{\text {tabel }}\right.$ ) sesuai dengan taraf signifikan yang telah ditentukan $\alpha=0,05$ ( $n-2$ ) yaitu 20-2 = 18 atau sebesar 0.444 .

\section{Tabel 4}

Hasil Instrument Uji Validitas

\begin{tabular}{|c|c|c|c|}
\hline No. & $\begin{array}{c}\text { Kualitas } \\
\text { Pelayanan }\end{array}$ & $\begin{array}{c}\text { WOM(Word Of } \\
\text { Mouth) }\end{array}$ & $\begin{array}{c}\text { Keputusan } \\
\text { Pembelian }\end{array}$ \\
\hline 1 & 0,647 & 0,772 & 0,680 \\
\hline 2 & 0,697 & 0,827 & 0,820 \\
\hline 3 & 0,775 & 0,564 & 0,842 \\
\hline 4 & 0,672 & 0,849 & 0,586 \\
\hline 5 & 0,665 & 0,808 & 0,825 \\
\hline 6 & 0,896 & 0,756 & 0,828 \\
\hline 7 & 0,667 & 0,529 & 0,804 \\
\hline 8 & 0,844 & $0,421 /$ tidak valid & 0,669 \\
\hline 9 & 0,629 & 0,684 & 0,888 \\
\hline 10 & 0,854 & 0,768 & 0,789 \\
\hline
\end{tabular}

Sumber Data: Hasil Olah Data

\subsubsection{Uji Hasil Reliabilitas}

"Reliabilitas adalah alat yang digunakan dalam penelitian untuk mengukur suatu kuesioner yang merupakan indikator dari variabel atau konstruk". (Ghozali 2016). Hasil Instrument Uji Reliabilitas sebagai berikut : 
Tabel 5

Uji Reliabilitas

\begin{tabular}{|c|c|c|c|}
\hline Variabel & $\begin{array}{c}\text { Cronbach's } \\
\text { Alpha }\end{array}$ & N & Keterangan \\
\hline Keputusan Pembelian (Y) & 0,923 & 10 & Reliabel \\
\hline Kualitas Pelayanan (X1) & 0,901 & 10 & Reliabel \\
\hline WOM (Word Of Mouth (X2) & 0,870 & 10 & Reliabel \\
\hline
\end{tabular}

Sumber : Hasil Pengolahan SPSS 22,

Hasil uji reliabilitas dapat diketahui bahwa nilai $\mathrm{r}$ alpha pada masing-masing variabel Keputusan Pembelian (Y) sebesar 0,923, Kualitas Pelayanan (X1)sebesar 0,901, dan WoM (Word Of Mouth) (X2) sebesar 0,870 yang berarti bernilai positif dan lebih besar dari nilai 0,60 artinya kuesioner pada ketiga variabel tersebut dinyatakan reliabel dan dapat digunakan sebagai instrumen dalam penelitian ini

\subsection{Uji Asumsi Klasik}

Pengujian asumsi klasik perlu dilakukan sebelum data di analisis lebih lanjut. Pengujian asmusi klasik yang dilakukan yaitu uji normalitas, uji multikolinearitas dan uji heteroskedastisitas.

\subsubsection{Uji Normalitas}

Pengujian ini dilakukan untuk menguji apakah nilai residual terdistribusi normal atau tidak. Pengajuan ini dilakukan dengan uji probability plot dan uji kolmogorov smirnov dengan nilai probabilitas signifikan $\mathrm{F}>5 \%$, maka residual terdistribusi normal dan jika probabilitas signifikan $\mathrm{F}<5 \%$, maka residual normal. Hasil pengujian gambar normal P-P Plot Of Regression Standarzed Residual 
Tabel 6

Kolmogorov Smirnov

\begin{tabular}{|ll|r|}
\hline Uji Normalitas & \multicolumn{2}{|c|}{$\begin{array}{c}\text { Unstandardized } \\
\text { Residual }\end{array}$} \\
\hline $\mathrm{N}$ & Mean & 100 \\
Normal Parameters ${ }^{\mathrm{a}, \mathrm{b}}$ & Std. Deviation & 2,17224998 \\
& Absolute &, 061 \\
& Positive &, 033 \\
Most Extreme Differences & Negative &,- 061 \\
& &, 615 \\
Kolmogorov-Smirnov Z & &, 844 \\
Asymp. Sig. (2-tailed) & & \\
& & \\
\end{tabular}

Sumber Data: Hasil Pengolahan data primer SPSS

Berdasarkan tabel 6 dapat diketahui bahwa data terdistribusi normal,hal ini dapat dilihat dari nilai Asymp. Sig. (2-tailed) 0,844 lebih besar dari 0,05 sehingga dapat disimpulkan bahwa data yang diuji berdistribusi normal.

Berdasarkan uji PP plot gambar 1 dapat diketahui sebagai berikut:

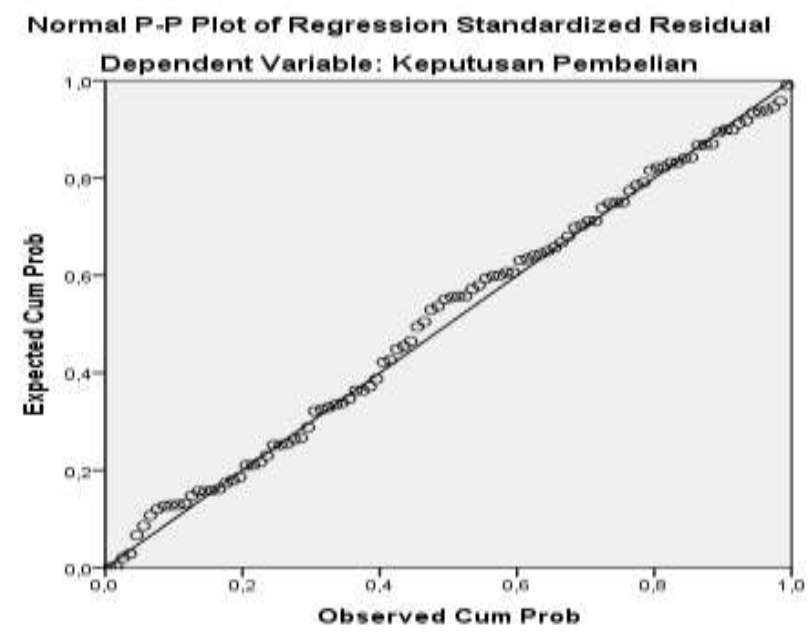

Sumber Data: Hasil Pengolahan data primer SPSS

Gambar 1

PP Plot 
Berdasarkan gambar 1 maka dapat terlihat titik-titik yang menyebar digaris diagonal dan penyebaran mengikuti arah garis diagonal, sehingga data pada variabel penelitian kualitas pelayanan, WOM (Word Of Mouth) dan keputusan pembelian terdistribusi normal dan dapat digunakan dalam model regresi karena memenuhi asumsi normalitas.

\subsubsection{Uji Multikolinieritas}

Uji multikolinieritas adalah suatu uji untuk melihat ada tidaknya hubungan yang tinggi antara variabel bebas dalam suatu model regresi linier berganda. Nilai untuk menunujukan ada tidaknya multikolinieritas adalah dengan melihat nilai tolerance $\mathrm{d}$.

Tabel 7 Uji Multikolinieritas

Coefficients $^{a}$

\begin{tabular}{|c|c|c|c|c|c|c|c|c|}
\hline \multirow[b]{2}{*}{ Model } & & \multicolumn{2}{|c|}{ Unstandardized Coefficients } & \multirow{2}{*}{$\begin{array}{c}\begin{array}{c}\text { Standardized } \\
\text { Coefficients }\end{array} \\
\text { Beta }\end{array}$} & \multirow[b]{2}{*}{$t$} & \multirow[b]{2}{*}{ Sig. } & \multicolumn{2}{|c|}{ Collinearity Statistics } \\
\hline & & $\mathrm{B}$ & Std. Error & & & & Tolerance & VIF \\
\hline 1 & (Constant) & 10,915 & 3,922 & & 2,783 &, 006 & & \\
\hline & Kualitas Pelayanan &, 253 &, 091 &, 248 & 2,783 &, 006 & 840 & 1,191 \\
\hline & WOM (Word Of Mouth) & 472 &, 094 &, 447 & 5,007 &, 000 & 840 & 1,191 \\
\hline
\end{tabular}

a. Dependent Variable: Keputusan Pembelian

Pada tabel 7 terlihat bahwa model regresi tidak mengalami gangguan multikolinieritas. Hal ini bisa dilihat pada nilai tolerance masing-masing variabel lebih besar dari 0,01 yaitu 0,840 dan hasil VIF juga menunjukan bahwa VIF variabel kurang dari 10 yaitu 1,191 jadi dapat disimpulkan bahwa tidak ada multikolinieritas.

\subsubsection{Uji Heteroskedastisitas}

Uji Heteroskedastisitas dilakukan untuk menguji apakah variable dalam penelitian memiliki varians yang sama atau tidak. Jika pada grafik scatterplot terlihat bahwa titik-titik yang ada menyebar secara acak atau tersebar baik diatas maupun dibawah angka 0 pada sumbu $Y$. 


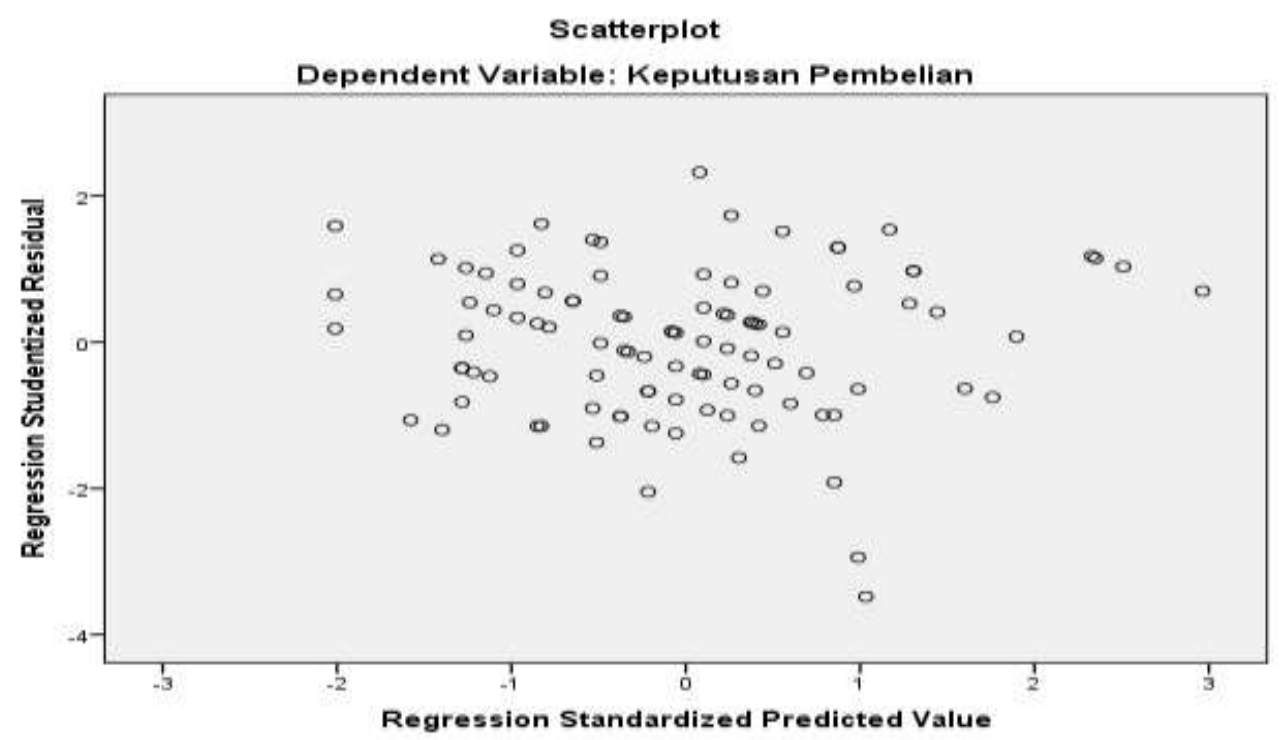

Sumber Data: Hasil Pengolahan data primer SPSS

\section{Gambar 2}

Berdasarkan gambar 2 maka dapat terlihat bahwa titik-titk tersebar diatas dan dibawah angka 0 pada sumbu $\mathrm{Y}$ dan titik-titik menyebar dan tidak membentuk pola tertentu, maka dapat disimpulkan bahwa tidak terjadi heteroskedastisitas.

\subsection{Analisis Regresi}

\subsubsection{Analisis Regresi Linier Sederhana}

Tabel 8 Hasil antara Kualitas Pelayanan terhadap Keputusan Pembelian

\begin{tabular}{|c|c|c|c|c|c|c|}
\hline & \multirow{2}{*}{ Model } & \multicolumn{2}{|c|}{ Unstandardized Coefficients } & $\begin{array}{l}\text { Standardized } \\
\text { Coefficients }\end{array}$ & \multirow{2}{*}{$\mathrm{t}$} & \multirow{2}{*}{ Sig. } \\
\hline & & B & $\begin{array}{l}\text { Std. } \\
\text { Error }\end{array}$ & Beta & & \\
\hline & (Constant) & 21,766 & 3,649 & \multirow[b]{2}{*}{,428 } & 5,966 &, 000 \\
\hline 1 & $\begin{array}{l}\text { Kualitas } \\
\text { Pelayanan }\end{array}$ & ,436 & ,093 & & 4,682 &, 000 \\
\hline
\end{tabular}

Sumber Data: Hasil Pengolahan SPSS

Berdasarkan tabel 8 hasil analisis antara $\mathrm{X} 1$ dan $\mathrm{Y}$ didapatkan persamaan regresi $: \mathrm{Y}=21,766+0,436 \mathrm{X} 1$ dengan Nilai $\mathrm{a}=21,766$ artinya jika tidak ada perubahan dari variabel Kualitas Pelayanan, maka Keputusan Pembelian adalah 21,766 dan Nilai b $=0,436$ artinya setiap penambahan satu skor atau nilai pada variabel Kualitas Pelayanan, maka Keputusan Pembelian akan meningkat 0,436 
KINERJA Jurnal Ekonomi dan Bisnis

Vol. 3 No. 1 - Desember 2020

Tabel 9 Hasil antara Word Of Mouth (WOM) terhadap Keputusan Pembelian

\begin{tabular}{|c|c|c|c|c|c|c|}
\hline \multirow{2}{*}{\multicolumn{2}{|c|}{ Model }} & \multicolumn{2}{|c|}{$\begin{array}{c}\text { Unstandardized } \\
\text { Coefficients }\end{array}$} & \multirow{2}{*}{$\begin{array}{c}\text { Standardized } \\
\text { Coefficients } \\
\text { Beta }\end{array}$} & \multirow[t]{2}{*}{$\mathrm{t}$} & \multirow[t]{2}{*}{ Sig. } \\
\hline & & B & Std. Error & & & \\
\hline & (Constant) & 16,817 & 3,411 & & 4,930 &, 000 \\
\hline 1 & $\begin{array}{l}\text { WOM (Word Of } \\
\text { Mouth) }\end{array}$ &, 576 & ,089 & ,547 & 6,462 & ,000 \\
\hline
\end{tabular}

Sumber Data: Hasil Pengolahan SPSS 
Berdasarkan tabel 9 hasil analisis antara X2 dan Y didapatkan persamaan regresi $\mathrm{Y}=16,817+0,576 \mathrm{X} 2$ maka Nilai $\mathrm{a}=16,817$ artinya jika tidak ada perubahan dari variabel Word Of Mouth, maka Keputusan Pembelian adalah 16,817 dan Nilai $b=$ 0,576 artinya setiap penambahan satu skor atau nilai pada variabel Word Of Mouth, maka Keputusan Pembelian akan meningkat 0,576

\subsection{Analisis Koefisien Determinan}

Besarnya kontribusi variabel independent mempengaruhi variabel dependent dapat diketahui dari nilai koefisien determinasi. Nilai koefisien determinasi atau R2 dapat dilihat pada tabel Model Summary kolom R Square sebagai berikut:

Tabel 10 Hasil Koefisien Determinasi

\begin{tabular}{|l|r|r|r|r|}
\hline Model & \multicolumn{1}{|c|}{$\mathrm{R}$} & R Square & $\begin{array}{c}\text { Adjusted R } \\
\text { Square }\end{array}$ & $\begin{array}{r}\text { Std. Error of } \\
\text { the Estimate }\end{array}$ \\
\hline 1 &, $592^{\mathrm{a}}$ &, 351 &, 337 & 2,195 \\
\hline
\end{tabular}

Sumber Data: Hasil Pengolahan SPSS

Hasil pengolahan data menunjukan bahwa nilai R2 sebesar 59,2\%, hal tersebut menggambarkan bahwa sumbangan kualitas pelayanan dan Word Of Mouth (WOM) terhadap keputusan pembelian di PT Hijrah Insan Karima adalah 59,2\% dan sisanya 40,8\% merupakan sumbangan dari variabel lain yang tidak diteliti dalam penelitian ini

\subsection{Analisis Korelasi}

\subsection{Korelasi Sederhana}

Analisis korelasi sederhana digunakan untuk mengetahui tingkat hubungan antara variabel bebas dan variabel terikat secara parsial. 


\section{Tabel 11 kualitas pelayanan terhadap keputusan pembelian}

\begin{tabular}{|l|r|r|r|r|}
\hline Model & \multicolumn{1}{|c|}{$\mathrm{R}$} & R Square & $\begin{array}{c}\text { Adjusted R } \\
\text { Square }\end{array}$ & $\begin{array}{r}\text { Std. Error of } \\
\text { the Estimate }\end{array}$ \\
\hline 1 &, $428^{\mathrm{a}}$ &, 183 &, 174 & 2,449 \\
\hline
\end{tabular}

Sumber Data: Hasil Pengolahan data primer SPSS

Berdasarkan tabel 11 diketahui bahwa nilai koefisien korelasi (r) kualitas pelayanan terhadap keputusan pembelian sebesar 0,428 , hal ini menunjukan bahwa adanya korelasi yang lemah.

\section{Tabel 12 Word Of Mouth (WOM) terhadap keputusan pembelian}

\begin{tabular}{|l|r|r|r|r|}
\hline Model & \multicolumn{1}{|c|}{$\mathrm{R}$} & $\mathrm{R}$ Square & $\begin{array}{c}\text { Adjusted R } \\
\text { Square }\end{array}$ & $\begin{array}{r}\text { Std. Error of } \\
\text { the Estimate }\end{array}$ \\
\hline 1 &, $547^{\mathrm{a}}$ &, 299 &, 292 & 2,269 \\
\hline
\end{tabular}

Sumber Data: Hasil Pengolahan data SPSS

Berdasarkan tabel 12 diketahui bahwa nilai koefisien korelasi (r) Word Of Mouth (WOM) terhadap keputusan pembelian sebesar 0,547, hal ini menunjukan bahwa adanya korelasi yang sedang.

\subsection{Uji Hipotesis}

\section{Uji T}

Uji ini dilakukan dengan membandingkan nilai thitung dengan nilai ttabel.

Tabel 13 Hasil Uji T

\begin{tabular}{|ll|c|c|}
\hline \multicolumn{1}{|c|}{ Model } & $\mathrm{t}$ & Sig. \\
\hline \multirow{2}{*}{$\begin{array}{l}\text { (Constant) } \\
\text { Kualitas }\end{array}$} & 2,783 &, 006 \\
& Pelayanan & & \\
& WOM (Word & 5,007 &, 000 \\
& Of Mouth) & & \\
\hline
\end{tabular}


Berdasarkan tabel 13 dapat diketahui bahwa nilai thitung untuk varibel kualitas pelayanan sebesar 2,783 dan nilai signifikan sebesar 0,006. Nilai thitung $(2,783)>$ $\mathrm{t}_{\text {tabel }}(1,984)$ dan nilai signifikan lebih kecil dari $0,05(0,006<0,05)$. Hal ini menunjukan bahwa H0 ditolak dan Ha diterima. Artinya, bahwa Kualitas Pelayanan berpengaruh positif dan signifikan terhadap keputusan pembelian terhadap PT. Hijrah Insan Karima. Demikian juga dengan nilai thitung untuk varibel WOM (Word Of Mouth) sebesar 5,007 dan nilai signifikan 0,0000. Nilai thitung $(5,007)>t_{\text {tabel }}$ $(1,984)$ dan nilai signifikan lebih kecil dari $0,05(0,000<0,05)$. Hal ini menunjukan bahwa H0 ditolak dan Ha diterima. Artinya, bahwa WOM (Word Of Mouth) berpengaruh positif dan signifikan terhadap keputusan pembelian terhadap PT. Hijrah Insan Karima.

\section{Pembahasan}

\section{Pengaruh Kualitas Pelayanan Terhadap Keputusan Pembelian}

Dari hasil penelitian uji hipotesis menunjukan bahwa kualitas pelayanan berpengaruh terhadap keputusan pembelian di PT. Hijrah insan karima / Histeel. Berdasarkan hasil uji $\mathrm{T}$ diperoleh nilai $t_{\text {hitung }}(2,783)>\mathrm{t}_{\text {tabel }}(1,984)$ dan nilai signifikan lebih kecil dari $0,05(0,006<0,05)$. Hal ini menunjukan apabila pelayanan dijalankan dengan baik dan berkualitas maka dapat meningkatkan keputusan konsumen untuk membeli produk di PT. Hijrah insan karima / Histeel Hal ini sesuai dengan hasil penelitian yang dilakukan oleh Leonardo Budi (2018) bahwa pelayanan yang berkualitas akan mempengaruhi keputusan pembelian.

\section{Pengaruh WOM (Word Of Mouth) Terhadap Keputusan Pembelian}

Dari hasil penelitian uji hipotesis menunjukan bahwa WOM (Word Of Mouth) berpengaruh terhadap keputusan pembelian di PT. Hijrah insan karima/ Hi /Histeel. Berdasarkan hasil uji $\mathrm{T}$ diperoleh nilai $t_{\text {hitung }}(5,007)>\mathrm{t}_{\text {tabel }}(1,984)$ dan nilai signifikan lebih kecil dari $0,05(0,000<0,05)$. Hal ini menunjukan bahwa H0 ditolak dan Ha diterima. Artinya bahwa WOM (Word Of Mouth) berpengaruh positif terhadap keputusan pembelian PT. Hijrah insan karima / Histeel. Hal ini sesuai dengan hasil penelitian yang dilakukan oleh dina lestari Purbawati (2018) bahwa WOM (Word Of Mouth) berpengaruh positif atau ada pengaruh terhadap keputusan pembelian. 


\section{Simpulan}

- Simpulan dapat diambil berdasarkan data yang telah dianalisis yang dapat menjawab rumusan masalah yang diuraikan oleh penulis, dan hasil yang diperoleh adalah sebagai berikut:

1. Kualitas pelayanan berpengaruh positif dan signifikan terhadap keputusan pembelian konsumen di Histeel/PT Hijrah Insan Karima. Hal ini menunjukan apabila kualitas pelayanan ditingkatkan atau dilakukan dengan baik maka akan meningkatkan keputusan pembelian konsumen di Histeel/PT Hijrah Insan Karima.

2. WOM (Word Of Mouth) berpengaruh positif dan signifikan terhadap keputusan pembelian konsumen di Histeel/PT Hijrah Insan Karima. Hal ini menunjukan apabila WOM (Word Of Mouth) ditingkatkan maka akan meningkatkan keputusan pembelian di Histeel/PT Hijrah Insan Karima.

\section{Saran}

Saran yang dapat disampaikan peneliti berdasarkan hasil penelitian diatas adalah:

1. PT Hijrah Insan Karima sebaiknya lebih memperhatikan lagi standar kualitas pelayanan yang diterapkan oleh perusahaan agar dapat meningkatkan keputusan pembelian. Karena konsumen maupun calon konsumen adalah image atau brand yang positif sehingga informasi dari mulut ke mulut atau WOM (Word Of Mouth) yang akan meningkatkan keputusan pembelian.

2. Sebaiknya perlu dilakukan penelitian yang lebih luas selain kualitas pelayanan dan WOM (Word Of Mouth) agar dapat lebih mengetahui faktorfaktor yang juga mempengaruhi keputusan pembelian 